\title{
Decision Support System for Matching Tractor - Implement System
}

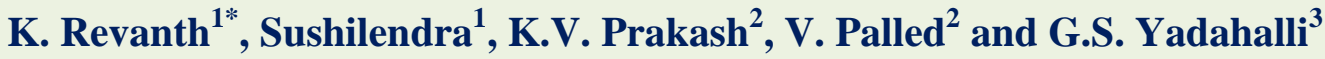 \\ ${ }^{1}$ Department FMPE, CAE, UAS, Raichur, Karnataka, India \\ ${ }^{2}$ Department REE, CAE, UAS, Raichur, Karnataka, India \\ ${ }^{3}$ Department of Agronomy, CoA Raichur, UAS, Raichur, Karnataka, India \\ *Corresponding author
}

\begin{abstract}
A B S T R A C T
Selection of tractor and implements has been very important aspect in farm mechanization

\section{Keywords}

Decision support system, Matching tractor, Implement system

Article Info

Accepted:

07 October 2018

Available Online:

10 November 2018

because of availability of variety of tractor models ranging from 15 to $75 \mathrm{~kW}$ and variety of implement sizes in the market. The main purpose of the study was to develop a computer based decision support system which could be able to predict the size of tractor required for an implement and vice-versa for a selected soil type and soil conditions. The decision support system was developed in visual studio platform using visual basic dot net programming language as front end MS Access as backend. The database contained the details of various tractor models and implement models available in the locality. Validation of developed decision support system was carried out and Paired T-test was conducted for predicted values and actual values available which showed that the predicted and actual values are insignificant @ $5 \%$ level of significance. The results showed that the DSS worked well in matching tractor power and implement sizes for better performance of the system.
\end{abstract}

\section{Introduction}

Agricultural mechanization aims at sustainable agricultural production by bringing lands under cultivation, saving energy and other resources, protecting the environment and increasing the overall economic welfare of the farmers. Machine and equipment are major inputs to agriculture.

Availability of adequate farm power is very crucial for timely farm operations for increasing production and productivity and handling the crop production to reduce losses (Srivastava, 2004). The growth in tractor production and sales in India has increased considerably during the last six decades. As a result, today around 300,000 tractors are sold annually. The average availability of tractors in the country is one tractor per 64 ha and the most popular size of tractor is in the range of 23-30 kW.

The selection of proper tractor and its matching implements is a difficult task which involves many decision-making processes that depend on different factors. These factors include tractor and implement specifications, soil conditions (firm, tilled or soft) and operational conditions (depth and speed of 
operation). A correct matching of tractorimplement system would result in decreased power losses, improved efficiency of operation, reduced operating costs and optimum utilization of capital on fixed costs (Zarini et al., 2013).

Computer programs are being used to assist farm managers and scientists in decisionmaking about how to manage machines or production operation and how to select machinery and power requirements (Alam and Awal, 2001). Computer models and simulation programs for predicting tractor performance help researchers to determine the relative importance of many factors affecting field performance of tractors without conducting expensive, as well as time consuming, field tests.

Decision support systems (DSS) is defined as an interactive computer-based system intended to help decision makers utilize data and models in order to identify and solve problems and make decisions. The application of DSS to farm management involves a range of opportunities and challenges. The latest years has seen mankind confronted with the problem of food security worldwide. Issues such as declining profitability of agriculture, climate variability and increasing concerns over the environmental impacts of farming pose complex challenges for farm management. DSS is based on the search for technology that can make agricultural systems more accessible and useful for guiding management of production systems. By considering all the above facts, the research was taken up.

Ishola et al., (2010) developed the database of tractor, implements and soil conditions. The databases of the tractors and implements could be edited and/or updated to suit the required task of the user. It presents the development of an interactive object-oriented program in Visual $\mathrm{C}++$ to predict tractor and implement system performance. Specifically, the program predicts the draft requirement for a given tillage implements and performance of a selected tractor by accessing the corresponding databases containing the required information. It also performed tractor and implement system simulation to predict a practical operating speed (as specified in ASABE standards) suitable for the tractorimplement combination and the performance parameters of the system. The simulation program finds the optimum practical field speeds for a given tractor and implements combination and predicts the tractorimplement system performance parameters.

Mehta et al., (2011) developed the database which consisted of data pertaining to tractors, implements, soils and other operating conditions. This paper demonstrated the application of DSS to select either an implement to match the tractor or to select a tractor to match the implement under different soil and operating conditions. The DSS leading to computer software developed in Visual Basic e-programming provided the intuitive user interfaces by linking databases such as specifications of tractors and implements, tractor performance data, soil and operating conditions, to support the decision on selection of tractor-implement system.

The programme predicts working width of implement based on input data for the most critical field operation and helped in selection of a suitable implement having width nearer to the predicted value among the commercially available implements. The software calculates the required drawbar power of the tractor based on draft and working speed of the selected implement. Finally, the PTO power requirement of a tractor was calculated by the software. Based on calculated PTO power, the software suggests available makes and models of tractor/machinery from the compiled data bank. 
Yousif et al., (2013) developed a computer system for farm management and selection of required farm machinery to perform field operations. Excel and Visual Basic software were used to develop the program. The software estimated the size and number of machine, power requirement and fuel consumption for implements and operation. The validation of developed computer system was done by testing the model. The predicted and actual values of field capacity, fuel consumption and implement width were compared. The root mean square of error between predicted and actual values was found to be very low. Paired T-test was also conducted, which indicated no significant difference between predicted and actual values at 5 per cent level of significance.

\section{Theoretical considerations}

\section{Selection of matching implement for a tractor}

The maximum working width of any implement can be calculated based on amount of power available at the power source. The other operational parameters required were soil conditions, type of soil, speed of operation and amount of draft that encountered per unit width of the implement.

The size of the implement is calculated by knowing maximum PTO power of the tractor that can be obtained from it. Then by knowing the soil conditions of the operation, the drawbar power required was calculated using the eqn. 20. The ratio of maximum PTO power to drawbar power for different soil conditions. The drawbar power is calculated using equation below (Zarini et al., 2013).

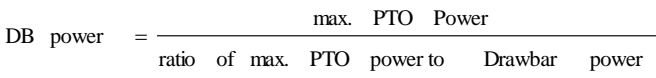

For the particular type of implement and the type of soil, the various operational parameters such as draft per unit width, speed of operation and field efficiency are as shown in Table 4. By the knowing all the values, the total draft required and the width of the implement was calculated by using the following expression (Jain and Philip, 2012).

Total draft $(\mathrm{kg})=\frac{\text { DBHP } \times 270}{\text { Speed }\left(\mathrm{km} \mathrm{h}^{-1}\right)}$

Width of implement $\quad(\mathrm{m})=\frac{\text { total draft }(\mathrm{kg})}{\text { draft per unit width }\left(\mathrm{kg} \mathrm{m}^{-1}\right)}$

Selection of matching tractor for the implement

The maximum power required of a source can be calculated by knowing the working width of the implement.

The other operational parameters required were soil conditions, type of soil, speed of operation and the amount of draft that encountered per unit width of the implement.

The maximum PTO power to perform a particular farm operation was calculated by knowing the working width of implement. By knowing the type of implement to be operated, type of soil and other operational parameters which are given in Table 4, total draft encountered during operation of the implement and drawbar power required to pull the implement were calculated as below (Jones and Bowers, 1977).

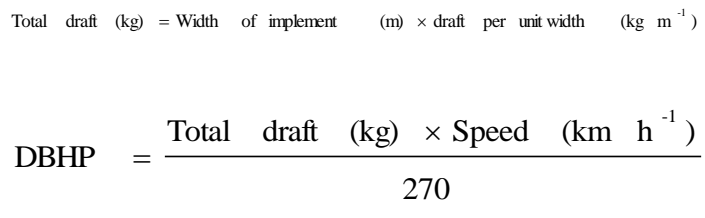

By knowing the DBHP required to pull the implement and the soil conditions of the field, the maximum PTO power of tractor required was calculated as below. 
Max. PTO HP $=$ DBHP $\times$ ratio of max. PTO HP to DBHP

\section{Development of decision support system}

The decision support system for cost and time estimation of selected farm operation has been developed with visual basic dot net as front end and MS Access as back end support. The database contains the information regarding tractor with their specifications such as make, model, rated power (HP, kW) and PTO HP. The database contains the information regarding primary tillage, secondary tillage and sowing implements with their required specifications. The database also contains the information regarding the drawbar power to PTO power conversion ratios for different soil conditions as shown in Table 1. The database included the draft, speed and field efficiency of different implements as shown in Table 2. Computer models are being used to assist farm managers and scientists in decision-making about how to manage and select their machinery effectively (Oskan and Edward, 1989). Models for machinery management are most useful when there is an interaction exchange of information during program operation between the computer and the user.

The decision support system finds out the matching tractor for an implement and vice versa. It is developed in the form of a computer program using the interactive controls and algorithms of Visual Basic programming language. The DSS model runs on a platform of Windows $95^{\mathrm{TM}}$ or above versions. The decision support system was developed in visual studio platform, which is one of the leading technologies in IT industry from recent past. It is best viewed at the screen resolution of $1366 \times 768$ pixels. The graphical user interface is the combination of pop-up windows, pull down menus, button controls and is more driven. The two components of the developed decision support system are described in Figure 1 and 2.
The developed decision support system was validated by testing of the model. The maximum working width of the selected implement was predicted based on the field parameters such as soil type, soil condition and operational parameters such as forward speed and draft. The predicted width of implement is compared with the nearest implement sizes available in the database.

The predicted and actual values of implement width was analysed using data analysis tools. Paired T-test was conducted to test the significance between predicted and actual values. Root mean square of error values were also calculated using the following equation.

RMSE $=\sqrt{\frac{1}{\mathrm{n}} \sum_{1}^{\mathrm{n}}(\text { predicted }- \text { actual })^{2}}$

Where,

$\mathrm{n}=$ number of observations

\section{Results and Discussion}

The developed decision support system starts with the splash screen displaying the name of the software, version of it and the 'start' button. Then displays the login page where user id and password has to be entered which verifies the genuine user as many user ids and passwords are pre-set in the database of the software. Once the user id and passwords are verified, the main home screen of the software will be displayed. It consists of title bar, menu bar, date and calendar and other details.

\section{Prediction of PTO power for selected implement (Matching tractor)}

The required PTO power for a mouldboard plough of width $0.6 \mathrm{~m}$ was $24 \mathrm{hp}$ for heavy draft soil under firm conditions was predicted (Fig. 3). 
Table.1 Maximum PTO power to DBHP ratio for different soil conditions

\begin{tabular}{|c|l|c|}
\hline Sl. No. & Soil conditions & Max. PTO HP to DBHP ratio \\
\hline $\mathbf{1}$ & Firm soil conditions & $1: 1.5$ \\
\hline $\mathbf{2}$ & Tilled soil conditions & $1: 1.8$ \\
\hline $\mathbf{3}$ & Soft soil conditions & $1: 2.1$ \\
\hline
\end{tabular}

(Jain and Philip, 2012)

Table.2 Draft, operational speed and field efficiency of various implements for different soil

\begin{tabular}{|c|c|c|c|c|c|}
\hline $\begin{array}{l}\text { Sl. } \\
\text { No. }\end{array}$ & Implement & Soil type & $\begin{array}{c}\text { Draft } \\
\left(\mathrm{Kg} \mathrm{m}^{-1}\right)\end{array}$ & $\begin{array}{c}\text { Speed } \\
\left(\mathrm{km} \mathrm{h}^{-1}\right)\end{array}$ & $\begin{array}{c}\text { Field } \\
\text { efficiency }(\%)\end{array}$ \\
\hline \multirow[t]{3}{*}{1} & \multirow{3}{*}{$\begin{array}{l}\text { Mouldboard } \\
\text { plough }\end{array}$} & Clayey or heavy draft & 1600 & 4.5 & 80 \\
\hline & & Silty or medium draft & 1400 & 5 & 80 \\
\hline & & Sandy or light draft & 1050 & 6 & 80 \\
\hline \multirow[t]{3}{*}{2} & \multirow[t]{3}{*}{ Disc plough } & Clayey or heavy draft & 1600 & 4.5 & 80 \\
\hline & & Silty or medium draft & 1400 & 5 & 80 \\
\hline & & Sandy or light draft & 1050 & 6 & 80 \\
\hline \multirow[t]{3}{*}{3} & \multirow[t]{3}{*}{ Disc harrow } & Clayey or heavy draft & 600 & 6 & 80 \\
\hline & & Silty or medium draft & 500 & 6 & 80 \\
\hline & & Sandy or light draft & 380 & 6 & 80 \\
\hline \multirow[t]{3}{*}{4} & \multirow[t]{3}{*}{ Cultivator } & Clayey or heavy draft & 450 & 6 & 80 \\
\hline & & Silty or medium draft & 300 & 6 & 80 \\
\hline & & Sandy or light draft & 150 & 6 & 80 \\
\hline \multirow[t]{3}{*}{5} & \multirow{3}{*}{$\begin{array}{l}\text { Seed cum } \\
\text { fertilizer } \\
\text { drill }\end{array}$} & Clayey or heavy draft & 150 & 5 & 70 \\
\hline & & Silty or medium draft & 90 & 5 & 70 \\
\hline & & Sandy or light draft & 50 & 5 & 70 \\
\hline \multirow[t]{3}{*}{6} & \multirow[t]{3}{*}{ Planter } & Clayey or heavy draft & 175 & 5 & 70 \\
\hline & & Silty or medium draft & 150 & 5 & 70 \\
\hline & & Sandy or light draft & 120 & 5 & 70 \\
\hline
\end{tabular}

Table.3 Comparison of predicted and actual values of implement width

\begin{tabular}{|c|l|c|c|c|}
\multirow{2}{*}{ SI. No. } & Implements & \multicolumn{3}{|c|}{ Implement width, m } \\
\cline { 3 - 5 } & & Predicted & Actual & Error, \% \\
\hline 1 & Mouldboard plough & 1.12 & 1.10 & 1.78 \\
\hline $\mathbf{2}$ & Disc harrow & 1.88 & 1.82 & 3.19 \\
\hline 3 & Cultivator & 2.5 & 2.45 & 2.00 \\
\hline & RMSE & \multicolumn{3}{|c|}{0.046} \\
\hline
\end{tabular}

RMSE - root mean square of error 
Table.4 Paired T- test for evaluation of predicted and actual values

\begin{tabular}{|c|l|c|}
\hline SI. No. & Parameter & Implement width, m \\
\hline $\mathbf{1}$ & Mean difference & 0.03 \\
\hline $\mathbf{2}$ & Standard deviation difference & 0.04359 \\
\hline $\mathbf{3}$ & Standard error mean & 0.02517 \\
\hline $\mathbf{4}$ & Degrees of freedom & 2 \\
\hline $\mathbf{5}$ & T value & 1.192 \\
\hline $\mathbf{6}$ & Probability of P, Significance (2 tailed) & 0.355 \\
\hline
\end{tabular}

Fig.1 Flowchart to find out the matching implement

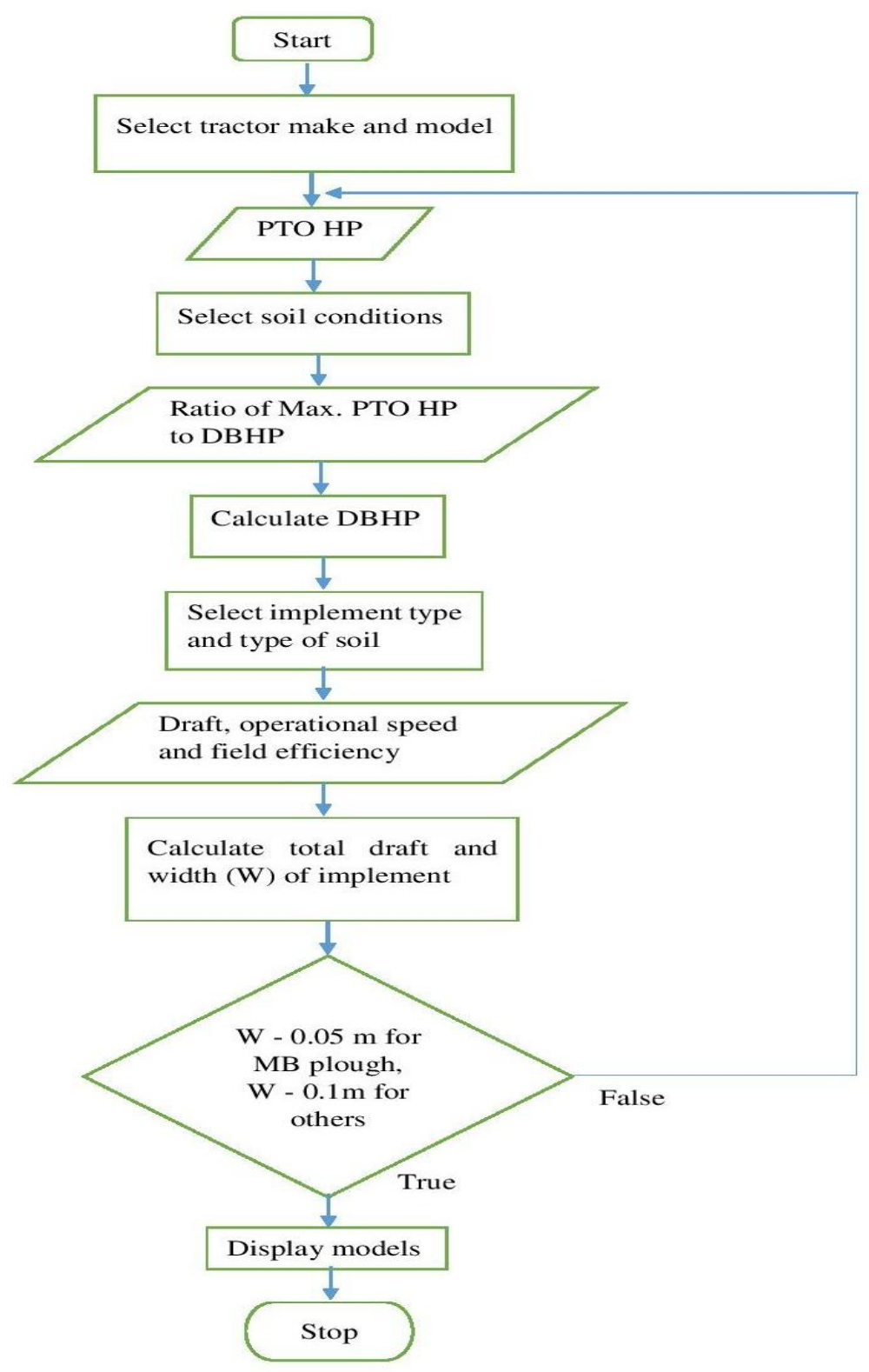


Fig.2 Flowchart to find out the matching tractor

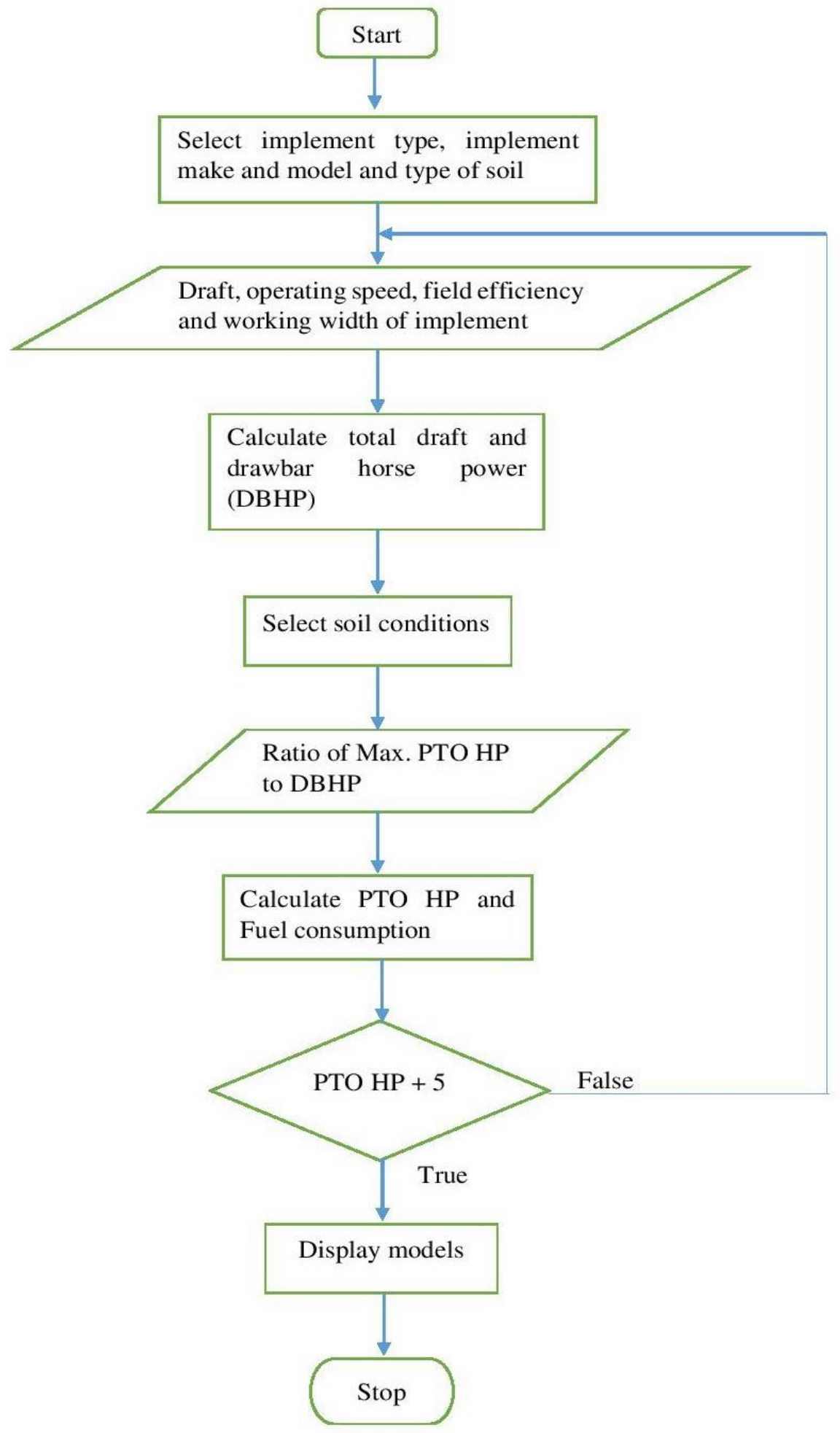


Fig.3 Prediction of PTO power of tractor for mouldboard plough

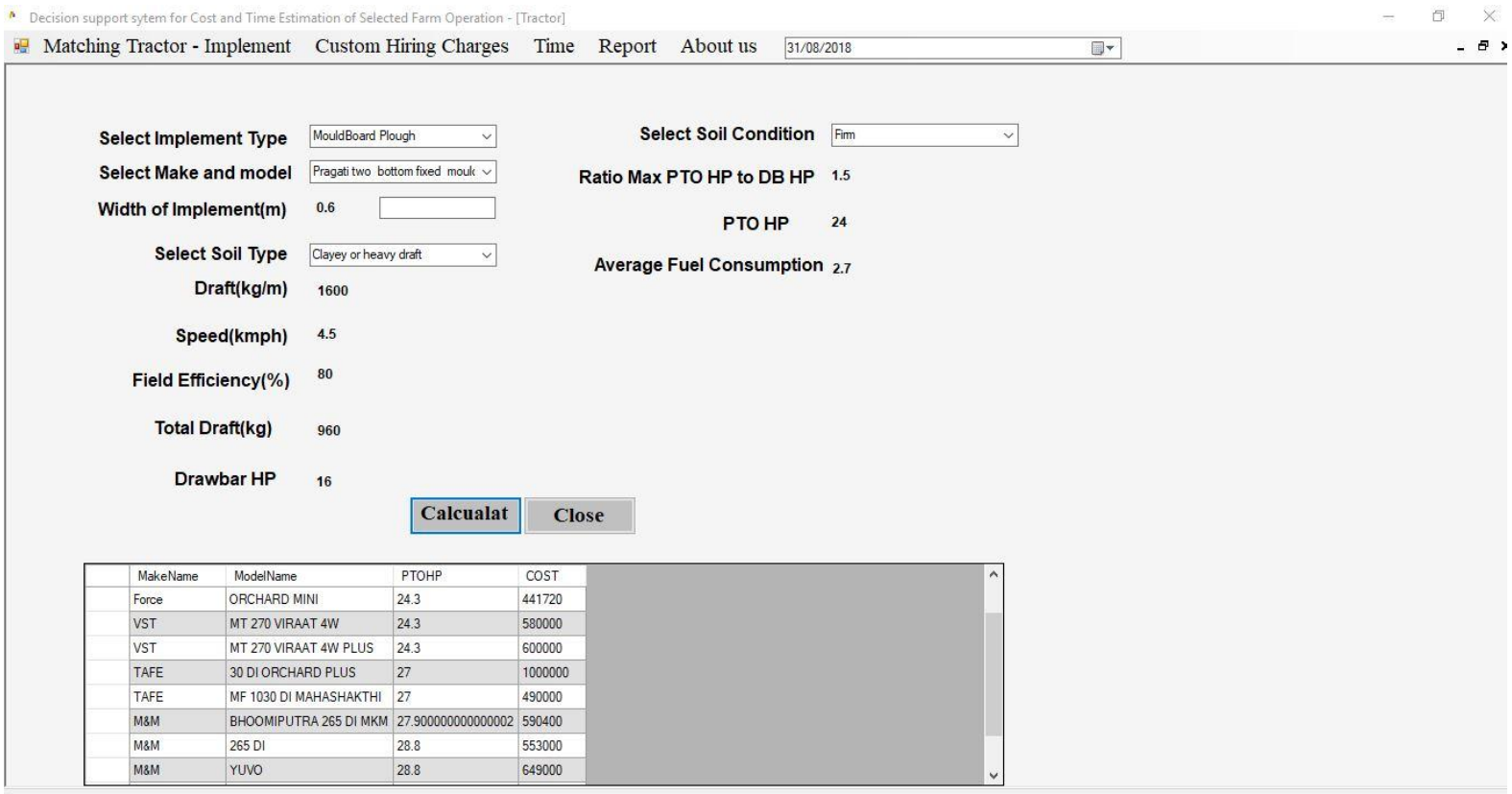

Fig.4 Prediction of width of mouldboard plough for a tractor

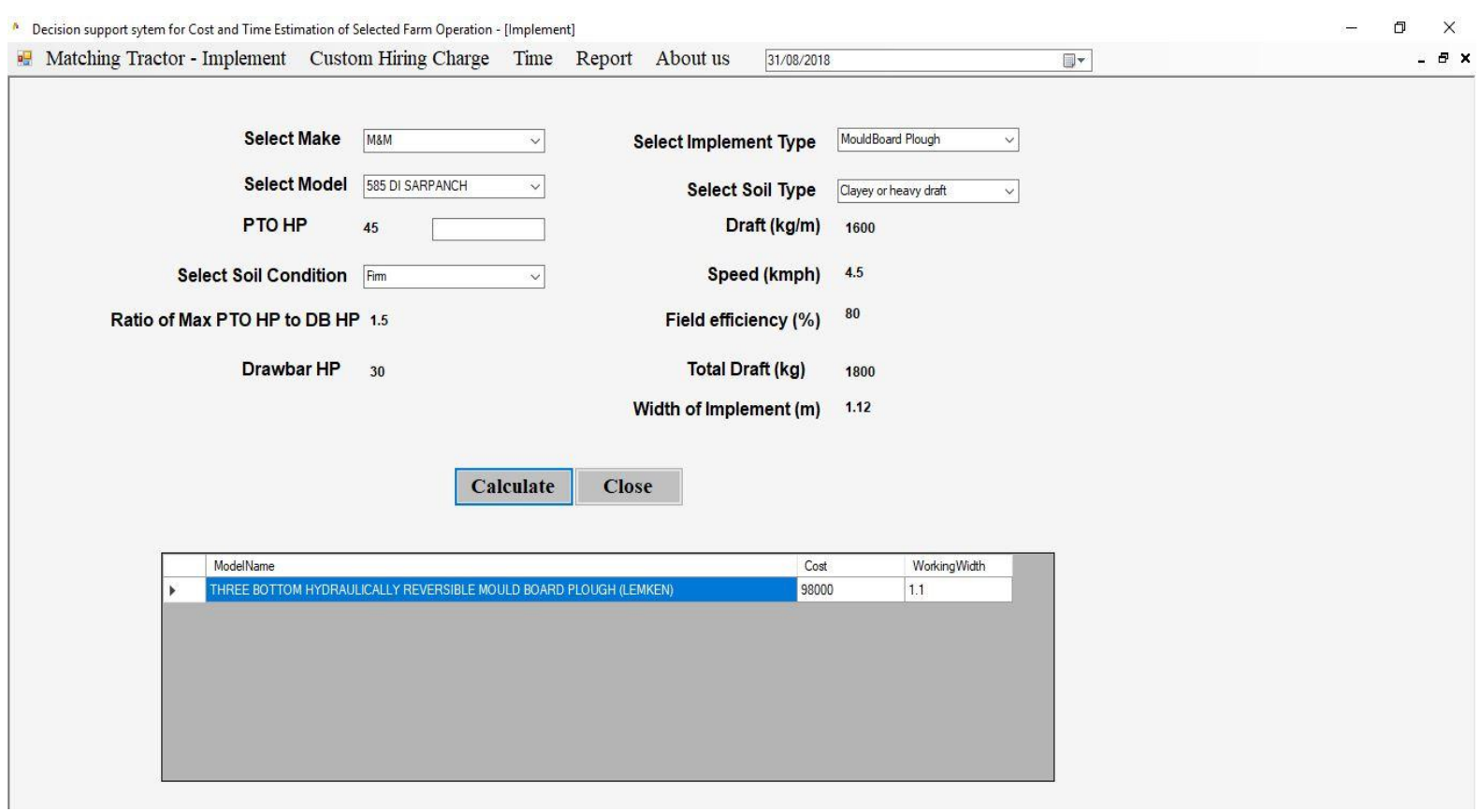

In the same line required PTO power for a disc harrow of width $1.72 \mathrm{~m}$ was $26.14 \mathrm{hp}$ for light draft soil under tilled conditions and cultivator of width $1.89 \mathrm{~m}$ was $22.68 \mathrm{hp}$ for medium draft soil under tilled conditions was predicted.

\section{Prediction of width of implement (Matching implement)}

For a tractor with 45 PTO hp, width of selected implement was estimated. A width of $1.12 \mathrm{~m}$ for mouldboard plough was estimated for heavy 
draft soil under firm conditions (Fig. 4). In the same line a width of $1.88 \mathrm{~m}$ for disc harrow was estimated for heavy draft soil under tilled conditions and a width of $2.5 \mathrm{~m}$ for cultivator was estimated for heavy draft soil under tilled conditions. The percentage error between predicted and actual width values were found to $1.78,3.19$ and 2.0 for mouldboard plough, disc harrow and cultivator, respectively as shown in Table 3. RMSE value was found to be 0.046 between predicted and actual values as indicated in Table 4.

The paired T-test indicates that there is no significant difference between actual and predicted values of implement width at $5 \%$ level of significance and results found were in same conformity with the results of Yousif et al., (2013).

The developed DSS accurately estimated the time required to perform selected field operations.

The developed DSS was more flexible and user friendly and most of the data was displayed on the screen.

The system can be used quickly, to explore the effect of changing one or more of input parameters on output values and thus helped in quick decision making.

The validation of developed DSS shows its effectiveness in predicting the cost and time of farm operations.

The predicted width of mouldboard plough for heavy draft soil under firm conditions, disc harrow for heavy draft soil under tilled conditions and cultivator for heavy draft soil under tilled condition for a tractor with 45 PTO hp were found to be $1.12,1.88$ and $2.5 \mathrm{~m}$, respectively.

The RMSE values implement width was found to 0.046 which is within the acceptable limits.

The developed Decision Support System was validated and analysed with paired T-test in SPSS statistical package and was found to be non-significant between sample mean predicted and actual values at $5 \%$ level of significance.

\section{References}

Alam, M. and Awal, M. A., 2001, Selection of farm power by using a computer program. $A M A$, 32(1): 65-68.

Ishola, T. A., Ogunlela, A. O. and Abubakar, M. S. A., 2010, An object oriented program for matching tractors and implements. Int. J. Engg. Tech., 10(2): 1-4.

Mehta, C. M., Singh, K. and Selvan, M. M., 2011, A decision support system for selection of tractor implement system used on Indian farms. $J$. Terramech., 48(1): 65-73.

Oskan, E. and Edward, M., 1989, A Farmer Oriented Machinery comparison Model. Trans. ASAE, 29 (3): $72-77$.

Srivastava, N. S. L., 2004, Farm power source, their availability and future requirement to sustain agricultural production. IARI, New Delhi. India, p: 36-44.

Yousif, L. A., Dahab, M. H. and El-Ramlawi, H. R., 2013, Crop machinery management system for field operations and farm machinery selection. J. Agril. Biotech. Sust. Dvpt., 5(5): 84-90.

Zarini, R. L., Akram, A., Alimardani, R. and Tabatabaekoloor, R., 2013, Development of decision support system of matching tractor implement system used on Iranian farms. Americ. J. Engg. Res., 2(7): 86-98.

\section{How to cite this article:}

Revanth, K., Sushilendra, K.V. Prakash, V. Palled and Yadahalli, G.S. 2018. Decision Support System for Matching Tractor - Implement System. Int.J.Curr.Microbiol.App.Sci. 7(11): 624-632.

doi: https://doi.org/10.20546/ijcmas.2018.711.076 